\title{
0675 TRANSFORMING COMMUNITIES TO PREVENT CHILD SEXUAL ABUSE AND EXPLOITATION: A PRIMARY PREVENTION APPROACH
}

L Cohen*, A Lyles, M Brown Correspondence: Prevention Institute, 221 Oak Street Oakland, CA 94607, USA

\subsection{6/ip.2010.029215.675}

While the health field has clearly made the case for the detrimental effects of child sexual abuse and exploitation, the responses to the problem have largely focused on after-thefact actions like incarceration and individual protection such as Internet safety. Preventing child sexual abuse will require a shift from individuals to environments and from fear to wellness. With support from Ms Foundation, Prevention Institute convened local and national leaders to identify an approach, framework and strategies that could be used to support this shift, cultivate investment in promising primary prevention strategies and foster continued dialogue to maximise change in communities. This session will include lessons learned from the process and ways to counter specific norms prevalent in the US and internationally that contribute to child sexual abuse though a primary prevention approach. Via interviews and a national convening, Prevention Institute facilitated a process that analysed environmental factors and norms that perpetuate abuse, and outlined policies and practices for transforming local communities and the national climate. The convening was structured to engender a critical, stimulating, and frank discussion among a broad range of practitioners and experts. During the process, attention was paid to distinct challenges and opportunities for prevention work in immigrant and other historically marginalised groups which are often overlooked. Based on the distilled research and critical thinking of a diverse group of local and national experts, an approach, framework and strategies that support efforts to prevent child sexual abuse in the first place were identified and broadly disseminated. 